\title{
COVID-19 IMPACT ON THE WORKERS OF THE INFORMAL SECTOR:
A LONGITUDINAL STUDY OF BANGLADESH
}

(D) Mahamuda Firoj
(i) Sharmina Khanom

(iD M Mamunur
Rashid $^{3}$
(D) Abeda Sultana
(iD) Humayun Kallol
(i) Mohammed Nazrul
Islam $^{6}$

Nair Sultana ${ }^{7}$

\author{
'PhD Research Fellow, BUP, Assistant Professor, Department of Economics \\ and Banking, International Islamic University Chittagong (IIUC), \\ Bangladesh. \\ Email:fmahamudacu@gmail.com \\ ${ }^{2,7}$ PhD Research Fellow, BUP, Lecturer, Department of Economics and \\ Banking, International Islamic University Chittagong (IIUC), Bangladesh. \\ ${ }^{3}$ PhD Research Fellow, BUP, Member, Harbour, and Marine: Payra Port \\ Authority, Bangladesh. \\ ${ }^{4}$ PhD Research Fellow, BUP, Assistant Professor, Department of Business \\ Administration, Premier University, Chittagong, Bangladesh. \\ ${ }^{5}$ PhD Research Fellow, BUP, Chairman: Payra Port Authority, Bangladesh. \\ ${ }^{6}$ PhD Research Fellow, BUP, Assistant General Manager, Bangladesh \\ House Building Finance Corporation, Dhaka, Bangladesh.
}

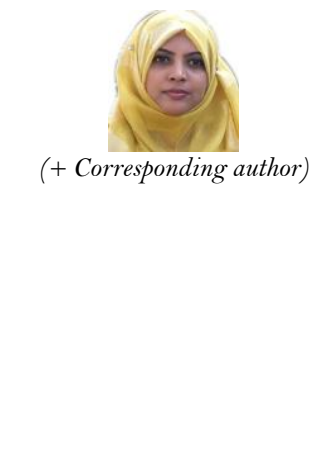

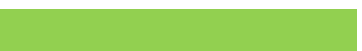

Article History

Received: 10 August 2021 Revised: 3 September 2021 Accepted: 24. September 2021 Published: 18 October 2021

\section{Keywords}

COVID-19

Longitudinal study

Informal sector

Vulnerable

Bangladesh

Socio-economic

JEL Classification:

A14, A19, E29, J46

\section{ABSTRACT}

The rapid spread of COVID-19 and subsequent restriction measures become a growing concern for its economic impacts as well. To address it, a study was undertaken to investigate the impacts upon the low-income people employed in the informal sectors in Bangladesh. The data of 372 respondents was collected through a structured questionnaire from the informal sectors in the cities of Dhaka and Chattogram, the most predominant hubs of the country's informal workers. This study covered the period of the first wave of the pandemic in Bangladesh from its first detection (8 March 2020) to the onset of the second wave (February 2021). It was a little over the one year period that had been divided into four-time segments considering as before pandemic (January - March 2020), and during pandemic (1st quartile: April - July 2020; 2nd quartile: August - November 2020 and 3rd quartile: December 2020 - February 2021). In the 1 st quartile during the pandemic, $65 \%$ of respondents' income revealed a sharp decline. This scenario continued in the 2 nd and 3rd quartiles with the figure of $35 \%$ and $24 \%$ respectively. Thus, in each of the three quartiles during pandemic time slots, the majority of respondents' consumption, living standard, schooling, and access to health care facilities were found negatively impacted. By the continuity of time some of the respondents were able to settle them in the new socio-economic condition. Overall, these results indicated several recommendations, including extending basic assistance to these vulnerable groups.

Contribution/ Originality: This study contributes to the existing literature which has been able to find that COVID-19 hardly affect the socio-economic condition of the people involved in the informal sectors of Bangladesh and the risk of informal workers falling under the extreme poverty line is getting higher.It also reveals that some of the informal workers have got used to the newly changed economic realities caused by COVID-19 by the continuity of time. 


\section{INTRODUCTION}

COVID-19 has emerged as a pandemic for over a year. Being originated in a town named Wuhan in China, it has spread all over the world with unprecedented speed and claimed over 3.2 million human lives to date. However, its toll has not stopped in taking lives only, rather it has forced thousands of businesses and services to close and put millions of humans out of jobs. Bangladesh has also been severely affected by the onslaught of the virus. And as a consequence, the country is currently experiencing an unprecedented lockdown with the second wave of Coronavirus. One year down the line, the country has seen again the highest figures of deaths with panic striking all over. However, apart from the deaths and widespread fear, the toughest toll has been taken by the Coronavirus is the livelihood of the lowermiddle-class people. A large portion of this population has lost their means of livelihood and has been forced to look for alternatives with increased workplace risk and reduced income or to live on charity. Therefore, in determining the impacts of the corona pandemic in terms of socio-economic, physiological, and psychological dimensions, a longitudinal study addressing the effect upon such vulnerable income groups has become a need of time.

The advent of the Corona Pandemic has already repainted the world purview, not only by creating the dire health crises but also by causing economic and social crises, disrupting the usual way of life and imposing unprecedented restrictions in the form of social distancing, staying at home, lockdowns and so on. Needless to say, the low-income segment of the population of a country not only bears the initial brunt but also remains vulnerable to any disastrous shocks of such a pandemic. Similarly, the informal sector workers, the lion's share of the labor force in Bangladesh, are thought to be the worst affected mass. To find out the impacts of COVID-19 on this class, with emphasis on the socioeconomic, physiological, psychological, and cultural/recreational aspects, several literatures (reports, newspaper, journals, etc.) have been surveyed. According to the COVID-19 weekly world, the epidemiological update of WHO as of $28^{\text {th }}$ February 2021 cumulative cases was $11,34,72,187$ and the cumulative deaths 25, 20,653 and the concurrent statistics in Bangladesh was 5, 46, 216 and 8,408Although the statistics displayed a less deplorable scenario of Bangladesh in comparison with many countries, it is well-understood that the country would find it more difficult to cope up with the economic effects of the pandemic. It is worth noting that the peculiarity of the crises is different from other common economic crises. A pandemic does not directly attack the economic framework rather it originates from the general living system of the community during pandemic. In a policy note titled "Impact of COVID-19 on informal workers," FAO termed the COVID-19 crisis as a major labor market shock with significant impacts in terms of unemployment and underemployment for informal workers who might eventually resort to negative coping strategies such as distress sale of assets, taking out loans from informal money-lenders, or resorting to child labor (FAO, 2020). The paper also expressed concerns over the additional risks and vulnerabilities that the informal sector employees are facing due to their exposure to unsafe work environments. In the case of Bangladesh, approximately 18 million workers along with their families are forced into serious uncertainty during the lockdown imposed from $26^{\text {th }}$ March to $31^{\text {st }}$ May 2020 (Islam, Islam, Mannan, Rahman, \& Islam, 2020). The urban informal economy was hit hard- both during and after shutdown having a loss of $6.78 \%$ of its pre-COVID workforce, said in the same report.

Social distancing, the mostly suggested means of preventing the contagious disease is advised to maintain stringently which has affected the social life especially the urban informal employees as the majority of them live in urban slums where they are fond of living together. This is also a challenge for them in queue up for relief and rations, traveling during holidays and festivals in crowded means of transport in observing the religious ceremonies to which people lean more during the stressful time (Sen, Honavar, Sharma, \& Sachdev, 2021). A perception-based assessment on COVID-19 of Bangladesh reveals that the decision of shutting down the normal life to retard the corona propagation, people might experience a mental and economic crisis (Bodrud-Doza, Shammi, Bahlman, Islam, \& Rahman, 2020). Several studies were conducted on the impacts of lockdown on mental health and found it detrimental in UK and Spain (Daly, Sutin, \& Robinson, 2020). The duration of lockdown restrictions and the quality of domestic living standards were found negatively related to the well-being of the residents in a study carried out in Italy by Pancani, Marinucci, Aureli, and Riva (2021). 
In a paper studied on the very early lockdown in China about the health, distress, and life satisfaction, it was observed that the people who stopped working fell in more severe mental and physical health discomfort as well as distress (Zhang, Wang, Rauch, \& Wei, 2020). A review undertaken to analyze the psychosocial impact of corona phobia, liable for multiples psychiatric manifestations in the different segments of society worldwide, has resulted in the findings that the forced confinement by nationwide lockdown can produce various mental diseases along with the long run post-traumatic stress disorder (PTSD). This also reported that the immature and deliberate propaganda by the media especially the social media with fake news, rumors, had fueled and caused the outbursts of racism, stigmatization, and xenophobia against particular communities (Dubey et al., 2020).

A very inclusive study conducted by Russo, Hanel, Altnickel, and van Berkel (2021) on using 50 psychological, social, situational, and physiological factors as predictor variables on the well-being and productivity of software engineers, who were working at home during the COVID-19 pandemic to find out the relation between the predictors and the dependent variables through a two-wave longitudinal data. They observed that well-beings were positively related to social contracts and negatively associated with distress in the confinement period. The boredom and distractions predicted productivity negatively at this similar period. They also instituted that all predictor variables were less significant in period two as the effects were mitigated through adaptation. This study has concluded that there are no significant difficulties for these software professionals with the interpretation that the nature of the job of software engineers is so sophisticated that they can cope up with the adverse situation through their urbane life and working style. A study by Buheji et al. (2020) analyzed the socio-economic impact of the pandemic on four different continents and detected that numerous difficulties were caused by it. The study shows how it is hard for the indigent to abide by social isolation or lock-down repressive measures.

The economic impact on the withdrawal of informal employees from the workforce was examined by the study of Ferreira dos Santos, de Santana Ribeiro, and Barbosa de Cerqueira (2020) which was implemented in Brazil during the Bahia pandemic of COVID-19, where 66 percent of informal employees were working. The study used the regional input-output matrix for the base year 2012 with 42 economic sectors, showing a reduction in the productive capacity of informal employees and significant economic negative consequences particularly in services sectors, the retirement of informal workers. The study revealed, however, that the income compensation program mitigates the negative effects by around 50\%. Another research (Aneja \& Ahuja, 2021) examined the effects of COVID-19 thus far on India's economy and society. There has been a disproportionate loss in all areas of the economy and even within a sector. The impact on society is also severe with employment losses, mental illness, increased household violence, etc. However, there are some beneficial consequences in terms of enhanced air quality, water quality, and biodiversity.

In a study on Indonesia's informal sector, Joko, Bagas, and Ikhwan (2020) examines the impacts of this pandemic together with empirical data, an online poll during the epidemic generated data utilized in the investigation. Theoretically, there are two perspectives on the functioning of the informal economy during a crisis: optimistic views that perceive a crisis as an informal economy and gloomy views that continue to lose the persisting informal economy and also the vulnerability of informal workers in a crisis. The research also examined how the COVID-19 epidemic has affected informal jobs and revenues, preparation to deal with the pandemic, and the circumstances of livelihood of informal workers. The impact on the informal sector in Indonesia of the COVID-19 pandemic crisis is distinct from that of Indonesia, particularly in 1997/98 and 2008/2009. This study gives a preliminary picture of the problem created by the COVID-19 epidemic affecting informal laborers both in agriculture and non-agriculture. Most respondents believed that their work and revenue were affected by the crisis. Informal employees are regarded as more vulnerable, in particular informal workers, because they do not have a clear guarantee of health or jobs.

Porsse, de Souza, Carvalho, and Vale (2020) has used a dynamic inter-regional CGE (Computable General Equilibrium) model to project COVID-19's economic impacts in Brazil. The study has pointed that higher morbidity and mortality due to the COVID-19 lowered labor supply in Brazil. Also discussed different fiscal policies of the government to counteract the pandemic but found those policies partially successful to mitigate the economic damages 
done by the outbreak of Covid-19. Ozili (2020) scrutinized the socio-economic impact of COVID-19 in African countries. The study used discourse analysis covering the period March 2020 to May 2020. This study also noted that the ongoing pandemic has affected the aviation sector, the financial, and the health care sector. The study has showed that the epidemic could also upsurge inequality, exclusion, discrimination, and global unemployment in Africa in the medium as well as long term. Temporary shutdown of educational institutions was negatively affecting over $85 \%$ of the student population in Africa - mentioned by the author. The study has also specified some common policies that have been adopted in African countries, namely, workplace closing cancel community events, restrictions on the congregation, close public transport, stay-at-home obligation, limits on internal movement, international travel controls, income support. The paper concludes with the comment that the COVID-19 pandemic also opens up many opportunities like enrichment of the capacity of health systems, protect jobs and workers, enhance social welfare legislation and programmers and also increase support for the agricultural sector. The socio-economic influence of the noble Coronavirus on 19 'Middle East and North Africa' (MENA) countries was analyzed by Hasan, Rabbani, and Abdulla (2021) where authors also highlighted the possible opportunities of Islamic finance in the post-pandemic period. In this study, the MENA countries were divided into three groups and the impact was analyzed for the period March 2020 to July 2020. The study exposed that economically most affected areas were the health sector, the stock market, the tourism sector, and due to the economic slowdown, unemployment, and poverty massive social misery were seen. Some economic advice from an Islamic perspective was outlined, for example, the 'Crisis Management Policies of Umar bin Khattab'. This study did not only scrutinize the impact of COVID-19 but also suggested different Islamic financial tools for short, medium, and long term support to recover the impact of COVID-19, such as like Zakat, Quard-Al Hasan, Islamic crowd funding, social SUKUK, etc. from the MENA region. Focusing on Bangladesh, Akter (2020) highlighted that the terrible claw of COVID-19 would reduce the income of about 50 million people who are currently engaged in various informal sectors. Using secondary information from numerous reliable sources the author portrayed the unemployment situation in six different sectors, namely, tourism, transport, export-import, remittance, $\mathrm{RMG}$, and banking and insurance which are most vulnerable in terms of rising unemployment. The author consciously emphasized the sufferings of around two million new graduates who come into the job market every single year in Bangladesh. The author concluded with the hope that this study would contribute positively to minimize this damage. The studies mentioned above so far deal with the overall effect of COVID-19 on the economy. In terms of indepth and detailed impact analysis, especially upon the lower-income segment of the population in Bangladesh, these surveyed studies are not sufficient. Therefore, it has become imperative to carry out an in-depth and on-ground study on the effect of COVID-19 on the working people employed in the informal sector of Bangladesh. This research is a humble endeavor to that extent.

\section{STUDY DESIGN}

This research has been a blend of qualitative and quantitative one. The main instrument of the study was a questionnaire survey. Details of the survey are as follows:

\subsection{Sample}

372 respondents (representing 372 households) were randomly chosen from the lower-middle-class city dwellers who are employed in informal sectors of the economy with no guaranteed jobs.

\subsection{Instruments}

A prepared and structured questionnaire has been the only research instrument. The questionnaire had subjective parts as well as quantitative parts. In the quantitative part, the respondents have been required to put their opinion on 5-point Likert scales, and deductions have been drawn on the analysis of the data. 


\subsection{Procedure}

The questionnaire has been read out by the interviewers to the respondents in person or over the mobile phone and their answers were noted down in papers. Data obtained through the interview have been analyzed and the results have determined the outcome of research.

\subsection{Data and Methodology}

As previously discussed, the research has been a blend of qualitative and quantitative one. The main instrument of the study was a questionnaire survey.

The target populations, 372 respondents (representing 372 households) were randomly chosen from among the lower-middle-class city dwellers who are employed in informal sectors of the economy with no guaranteed jobs in Dhaka and Chattogram two metropolitan cities of Bangladesh. The demographic data were also taken and it was found that the respondent households consisted of only family members. Hence, the researchers used 'household' and 'family' interchangeably in the research.

\subsubsection{Selection of Respondents}

They were chosen from the metropolitan cities of Dhaka and Chattogram. Efforts were taken to keep the group harmonious, and in doing so, people who face the same or similar economic realities were chosen as respondents.

For example, all the respondents have their household members in the cities and not in their rural origins. The people who do not have a fixed job or their job were threatened by the changes in socio-economic realities of the area due to the pandemic were randomly selected as the respondents. Furthermore, they were clear representatives of their households.

\subsubsection{Longitudinal Time Duration}

The study has been a longitudinal one. It has been an aim to study the conditions of the lower-middle-class city dwellers over time.

As is known, in Bangladesh, the COVID-19 virus was detected on 8 March 2020. Since then, a little over one year has elapsed till the recent second wave came up. This one year has been divided into four segments as under in Table 1:

Table-1. The longitudinal time duration of the study.

\begin{tabular}{c|c|l}
\hline Title & Duration & Consideration for Selection \\
\hline Before Pandemic & $\begin{array}{c}\text { January-March } \\
2020\end{array}$ & $\begin{array}{l}\text { To ascertain the conditions of the respondents before } \\
\text { the arrival of COVID-19 in Bangladesh. }\end{array}$ \\
\hline $\begin{array}{c}\text { During Pandemic } \\
\left(1^{\text {st }} \text { Quartile }\right)\end{array}$ & $\begin{array}{c}\text { April-July 2020 } \\
\text { To ascertain the conditions of the respondents during } \\
\text { the initial onslaught of COVID-19, which has been a } \\
\text { mix of confusion and instability. }\end{array}$ \\
\hline $\begin{array}{c}\text { During Pandemic } \\
\left(2^{\text {nd }} \text { Quartile }\right)\end{array}$ & $\begin{array}{c}\text { August-November } \\
2020\end{array}$ & $\begin{array}{l}\text { To ascertain the conditions of the respondents after } \\
\text { stabilization. }\end{array}$ \\
\hline $\begin{array}{c}\text { During Pandemic } \\
\left.\text { ( }{ }^{\text {rd }} \text { Quartile }\right)\end{array}$ & $\begin{array}{c}\text { December } 2020- \\
\text { February } 2021\end{array}$ & $\begin{array}{l}\text { To ascertain the conditions of the respondents at the } \\
\text { last stage of the first wave. }\end{array}$ \\
\hline
\end{tabular}

\subsubsection{Approaches of Data Collection}

Researchers examined some other methods of data collection also. Apart from the structured questionnaire, the researchers considered in-person interviews as data collection and validation methods.

However, the researchers considered that one or more Focused Group discussions (FGD) could have been of much use, but it could not be done due to the risk of COVID-19 itself. 


\section{RESULT AND DISCUSSION}

\subsection{Demographic Characteristics of the Sample Respondent}

Demographic characteristics include place, sex, marital status, and educational status. The researchers considered 372 valid respondents where $51.61 \%$ are from Chattogram and $48.39 \%$ are from Dhaka cities as the sample. Almost $90.32 \%$ of them are male and $9.68 \%$ are female and the average age is 38 years. Among the respondents, $85.48 \%$ are married and have an average of 5 members in their household. Every household has an average of 2 children. In general, it was found that one single family member is being employed and acts as the breadwinner for the entire household. As for education, 42.74 of respondents had completed the secondary level of education and approximately $10 \%$ of them had no more knowledge about schooling Table 2.

Table-2. Demographic characteristics of the sample respondent.

\begin{tabular}{|c|c|c|c|c|c|}
\hline Characteristics & Number & Percentage & Mean & Standard Deviation & Range \\
\hline \multicolumn{3}{|l|}{ Place } & & & \\
\hline Dhaka & 180 & 48.39 & & & \\
\hline Chattogram & 192 & 51.61 & & & \\
\hline Total & 372 & & & & \\
\hline \multicolumn{3}{|l|}{ Sex } & & & \\
\hline Male & 336 & 90.32 & & & \\
\hline Female & 36 & 9.68 & & & \\
\hline Total & 372 & & & & \\
\hline Marital Status & 324 & 85.48 & & & \\
\hline Married & 54 & 14.52 & & & \\
\hline Unmarried & 372 & & & & \\
\hline \multicolumn{3}{|l|}{ Total } & & & \\
\hline \multicolumn{3}{|c|}{ Educational Status } & & & \\
\hline No school & 36 & 9.68 & & & \\
\hline Primary & 96 & 25.81 & & & \\
\hline Secondary & 159 & 42.74 & & & \\
\hline Tertiary & 27 & 21.77 & & & \\
\hline Total & 372 & & & & \\
\hline \multicolumn{3}{|c|}{ Respondents Age (years old) } & & & \\
\hline $20-30$ & 81 & 21.77 & & & \\
\hline $31-40$ & 177 & 47.58 & & & \\
\hline $41-50$ & 87 & 23.39 & 37.93 & 0.78 & $20-70$ \\
\hline $51-60$ & 21 & 5.65 & & & \\
\hline $61-70$ & 6 & 1.61 & & & \\
\hline Total & 372 & & & & \\
\hline \multicolumn{6}{|c|}{ Number of the family members } \\
\hline 3-Jan & 51 & 13.71 & & & \\
\hline 6-Apr & 282 & 75.81 & 4.9 & 0.23 & 10-Jan \\
\hline 10-Jul & 39 & 10.48 & & & \\
\hline Total & 372 & & & & \\
\hline \multicolumn{6}{|c|}{ Number of children (persons) } \\
\hline $0-1$ & 144 & 38.71 & & & \\
\hline $3-\mathrm{Feb}$ & 165 & 44.35 & 1.72 & 0.09 & $\mathrm{O}-4$ \\
\hline 4-Mar & 63 & 16.94 & & & \\
\hline Total & 372 & & & & \\
\hline \multicolumn{6}{|c|}{$\begin{array}{l}\text { Number of earning members of } \\
\text { the family (persons) }\end{array}$} \\
\hline $0-1$ & 267 & 71.78 & & & \\
\hline 3-Feb & 102 & 27.42 & 1.08 & 0.09 & 4-Jan \\
\hline $5-\mathrm{Apr}$ & 3 & 0.8 & & & \\
\hline Total & 372 & & & & \\
\hline
\end{tabular}




\subsection{Social and Economic Impact of COVID-19}

The study categorized 13 different types of employment status of the respondent Table 3. It has been found that, before the pandemic, petty traders cover the largest group (19.35\%), and barbers cover the smallest one $(2.42 \%)$. During the pandemic, the scenario has become quite different because many of the respondents changed their occupations several times. From Table 3 it is observable that in most of the occupations, income is declining; and this rate is high in the 1st quartile when COVID-19 started to spread. In the 2nd and 3rd quartile, income is started recovering in many of the cases, but the rate is very slow. Monthly income saw a decrease of $32 \%$ on average during the pandemic. The average income of all three time-slots is 8508 Taka which supports the family having 5 members on average. It indicates that the risk of informal workers falling under the extreme poverty line is higher. This finding is in line with the findings of Komin, Thepparp, Subsing, and Engstrom (2021) in Thailand. Another important fact is that the number of unemployed respondents during the 1st quartile is 63, cover the largest group in those months. The very early period of the pandemic increase the unemployment rate, and gradually it falls with rising time.

Figure 1 reveals the overall pattern of the change of income during the pandemic. In the 1st quartile, almost $65 \%$ of the respondents' income saw a sharp decrease. This finding coincides with the findings of Kartseva and Kuznetsova (2020) in Russia. They found that every second worker became vulnerable where young workers were losing their income much. The initial shock associated with the arrival of COVID-19 during March and April 2020 might be liable for this. During the 2 nd and 3rd quartiles, this scenario is continued and almost $35 \%$ and $24 \%$ of respondents lost their income. In the 2 nd and 3rd quartile, a significant no of respondents could increase their income. One notable fact is that in 3rd quartile income has been stable for the majority (almost $41 \%$ ) of the respondents. This indicates that people have got used to the newly changed economic realities caused by COVID19.

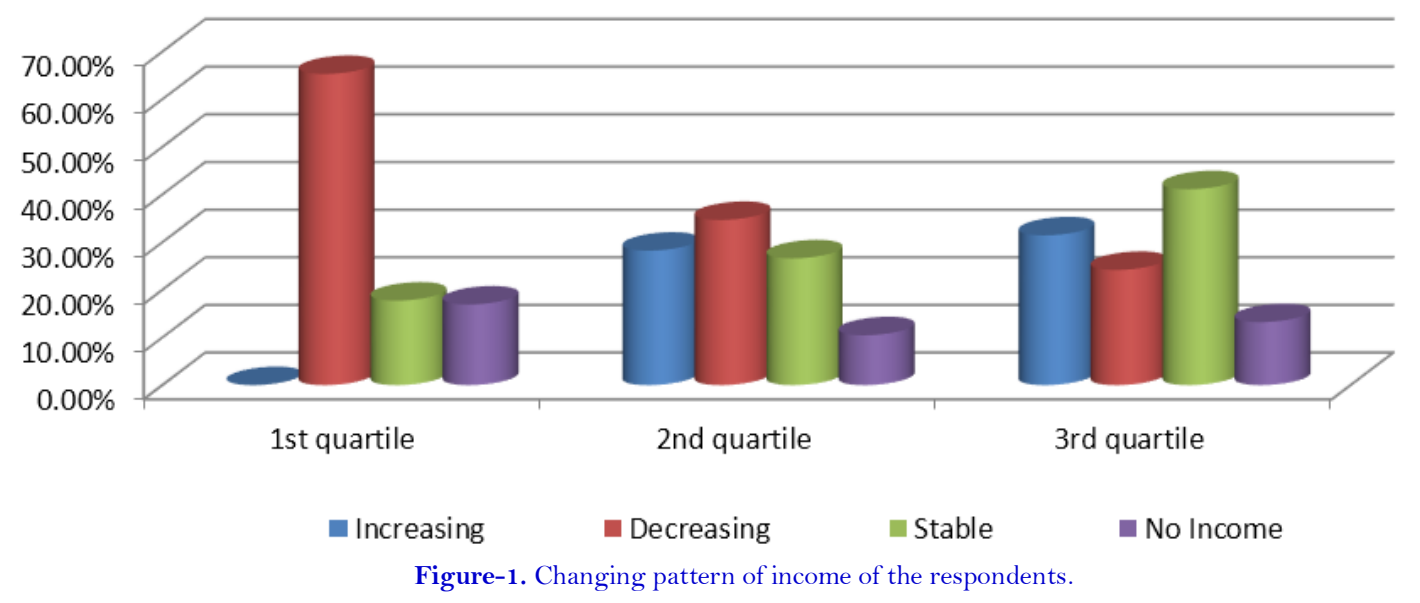

In the pandemic situation people of the informal sector have to change their occupation and job providers/employers several times. In this study from March 2020 to February 2021, almost 30\% of the total respondents changed their occupations for once, while $14.52 \%$ changed twice and $3.13 \%$ changed their occupations more than two times (Figure 2). This vividly reveals the vulnerability in which the informal workers find themselves. In the context of new occupational status, $69 \%$ of the respondents find lower pecuniary facilities in the new job, while $29 \%$ had to choose a transitory job and only $2 \%$ of the respondents could find better opportunities in the new job. 
Table-3. The change of income, and occupation.

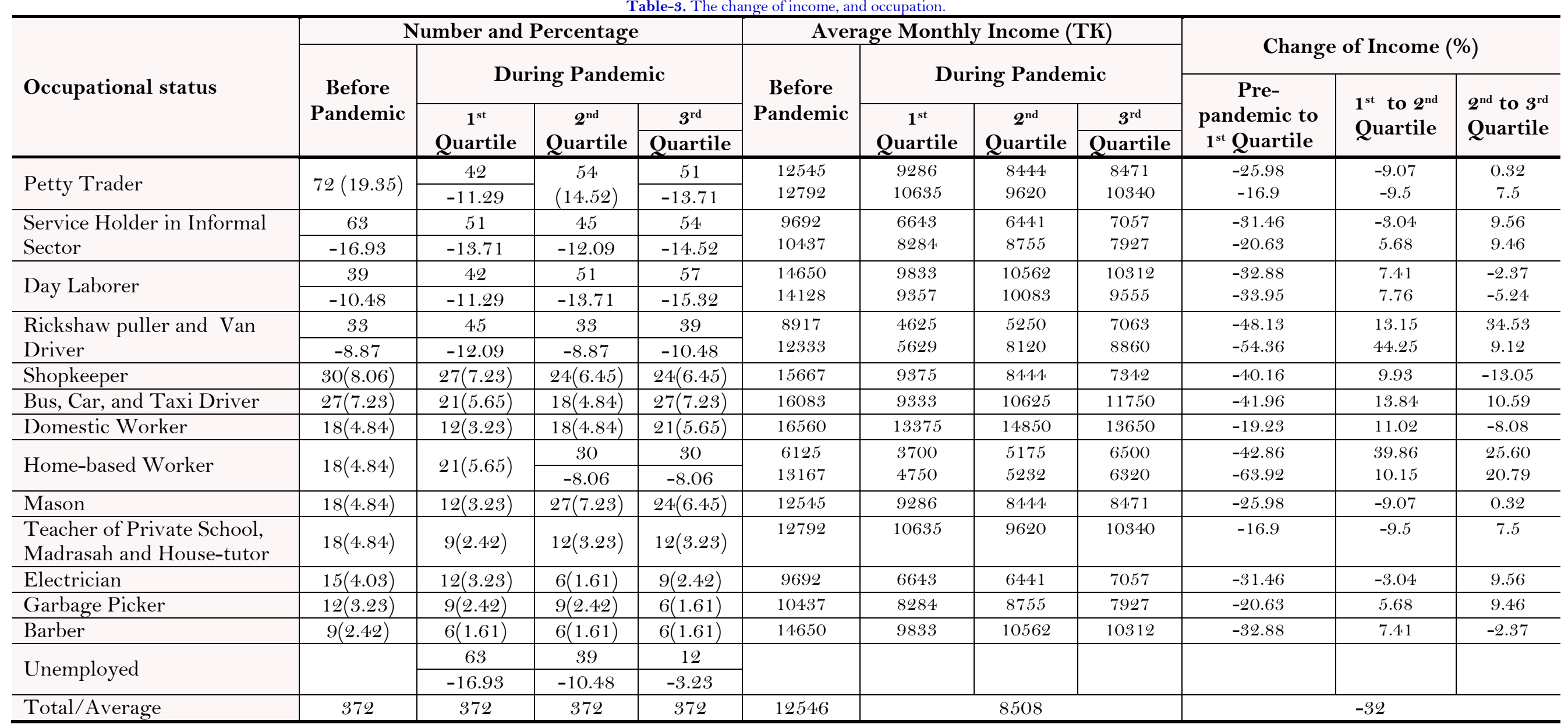




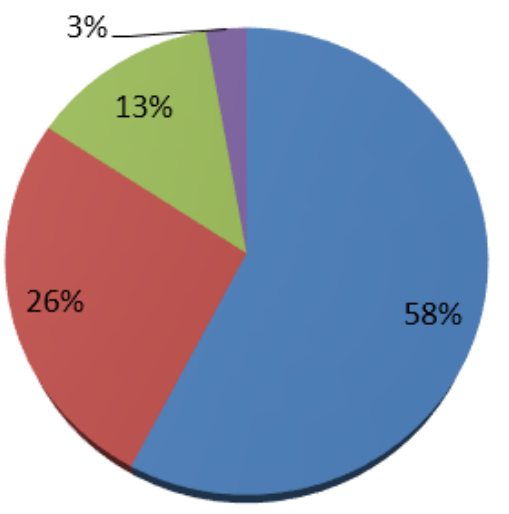

No. of Change

- Change for One Time

Change for Two Times

- Change for More then Two Times

Figure-2. No. of changes in occupational status

Overall, $62.9 \%$ of the respondents think that COVID-19 creates a serious threat to their well-being, income, and productivity; while $33.87 \%$ find it a moderate threat and only $3.12 \%$ consider it not a threat at all.

The study also tries to recognize the effect of income change on the workers of the informal sector from a socio-economic livelihood's perspective. For this purpose, some effects have been categorized concerning respondents' priorities in different time variants. For example, one of the respondents mentioned that, among many other problems, the crucial one was the fact that in the 1 st 4 months after the spread of COVID-19 he had to resort to a much lower level of household consumption and living standards. Figure 3 illustrates that in 1st quartile March to June $202026.61 \%$ of respondents reduce their consumption and living standard, and $21.77 \%$ had to stop their children's education because of low income. The major effect on the 2 nd quartile was, $21.77 \%$ had to send their spouse to the working sector and $17 \%$ of the respondents expanded their working time to cover up lost earnings. In the $3 r d$ quartile, $27 \%$ of the respondents faced serious crises to meet the daily necessities, which further strengthens the fact of the gradual vulnerability of the workers of the informal sector. In each of the three quartiles, a significant number of respondents either consumed from their savings or increased the debt of the family. This might have caused them to fall into a poverty trap.

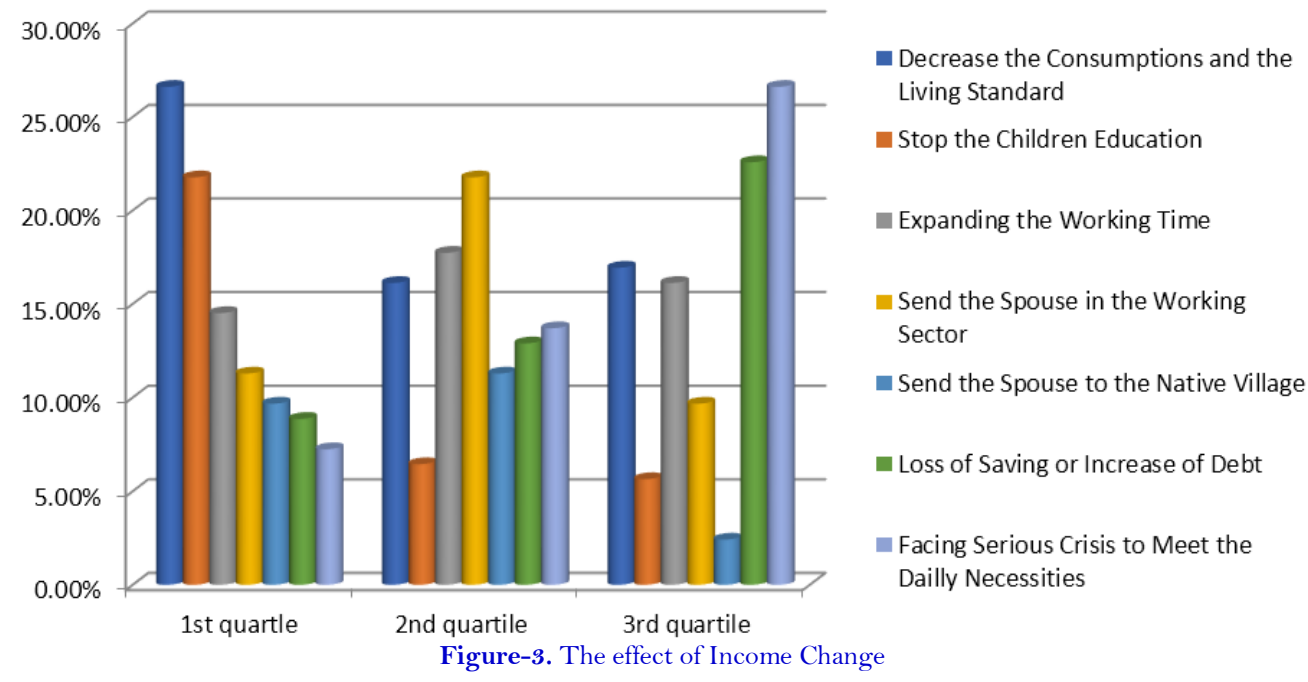

Bangladesh's point-to-point normal inflation rate has increased to 5.50\% in October 2020, (Bangladesh Bank, 2020) the highest in 7 years, amid the COVID-19 pandemic. This study tries to unearth the actual scenario of the real income of the respondents in terms of purchasing power. But the study reveals the crucial truth that above $80 \%$ of the respondent's purchasing power decreased in every quartile (Figure 4). 


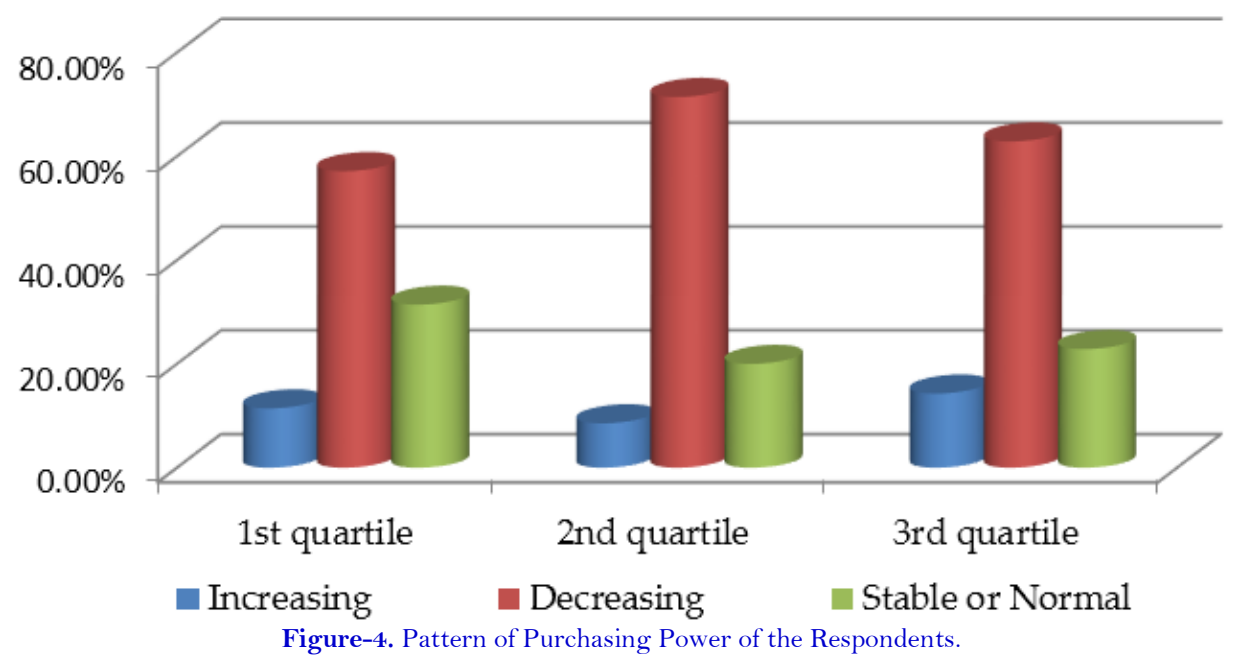

In the pandemic situation, different government bodies, private organizations, wealthy people, social welfare organizations have been providing financial assistance for vulnerable groups. In this study, only $25 \%$ had access financial support from different sources. Compared to neighboring India, it is inadequate as Sumalatha, Bhat, and Chitra (2021) said 70\% of India's domestic workers received the state government's assistance in the epidemic in the form of food or ration. However, according to respondents' answers in each of the three quartiles, active sources were the government and wealthy individuals in the locality.

In Bangladesh from 20th March 2020, all educational institutions have been closed. In our survey, about $86 \%$ (321) of the respondents have school-going children. Among them, about 58\% of respondents mention that their children have not attachment to education as their schools are off and many of them (almost $27 \%$ ) involve in the income-generating process. Figure 5 and 6 describe the motion of education and the system of education of those who are attached to education respectively.

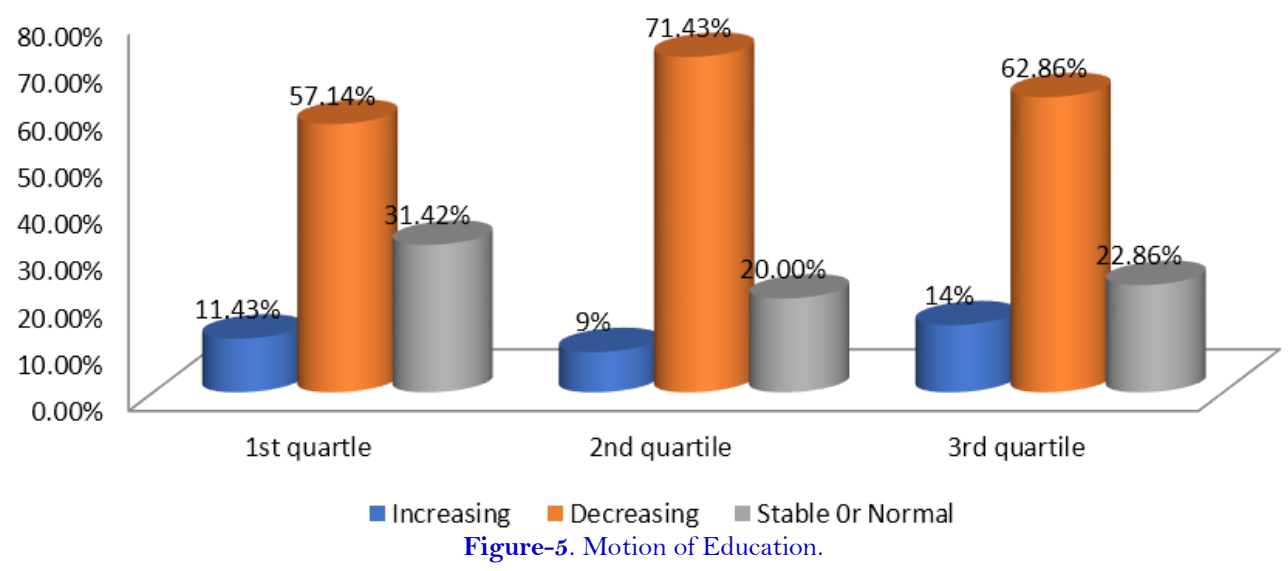

The majority of the respondents mentioned the decreasing wave of their child education in each quartile. The picture is the same almost everywhere on the earth, notably (Jena, 2020) reported that about 32 crore students ditched from different levels of schooling during the pandemic in India. In this study, the maximum number of respondents' children performed normal education at home, while providing help to the family members in the pandemic time, which was possible due to the awareness of the parents. A few respondents were covered in the assignment base assessment of government primary and secondary schools. Due to poor technological involvement and the financial crisis, a small portion of them was regular in online classes and televised remote learning in every quartile. 


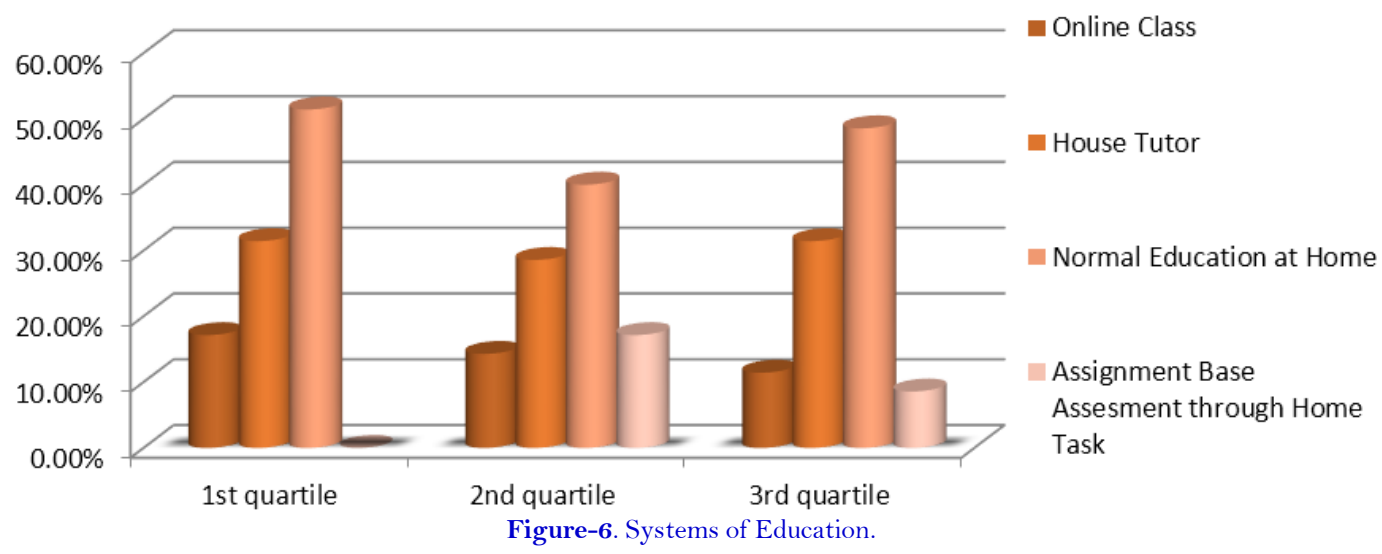

\subsection{Physiological and Psychological Impact}

In Bangladesh, after the first outbreak of COVID-19 on March 8, 2020, a total of 546216 people were infected and Bangladesh is the top 33rd country in the world till February 28, 2021. (http://iedcr.gov.bd). Comparing to the national scenario, the ongoing study has to find a $7.25 \%$ positivity rate of getting infected, among the workers of informal sectors of the top two infected districts - Dhaka (17\%) and Chattogram (8\%). About $55.56 \%$ of the patients who fall sick with COVID-19 have experienced mild complications after recovery and another $44.44 \%$ of patients with positivity recover completely without any post COVID complications Figure 7.

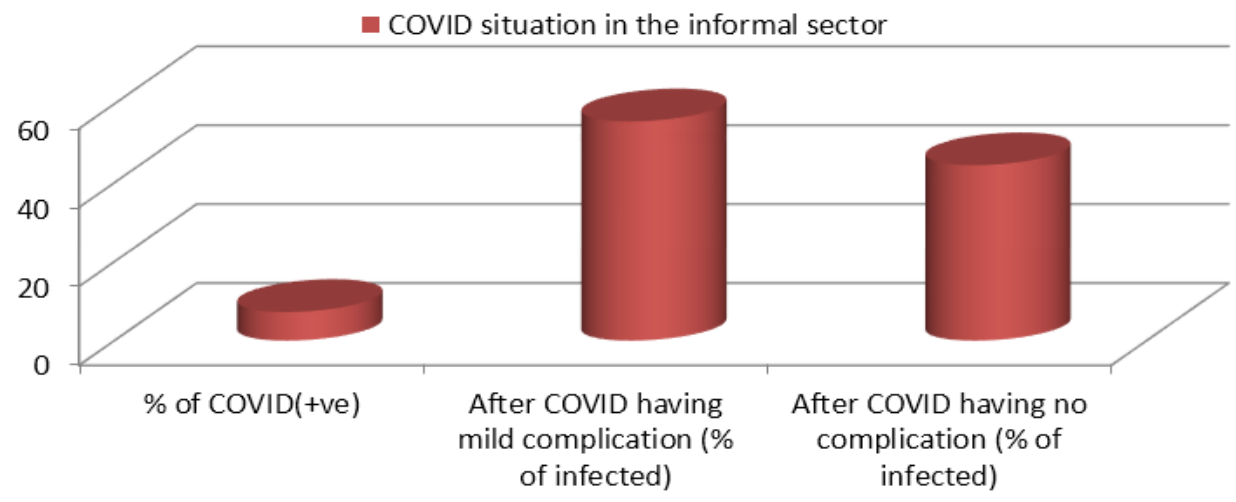

Figure-7. The COVID situation in the informal sector

In the 14th month of the ongoing pandemic, the rate of people with sound health is $92.74 \%$, but they are worried to contract COVID-19 soon. This study also reveals how people think about the chance of getting contracted by this virus Figure 8 .

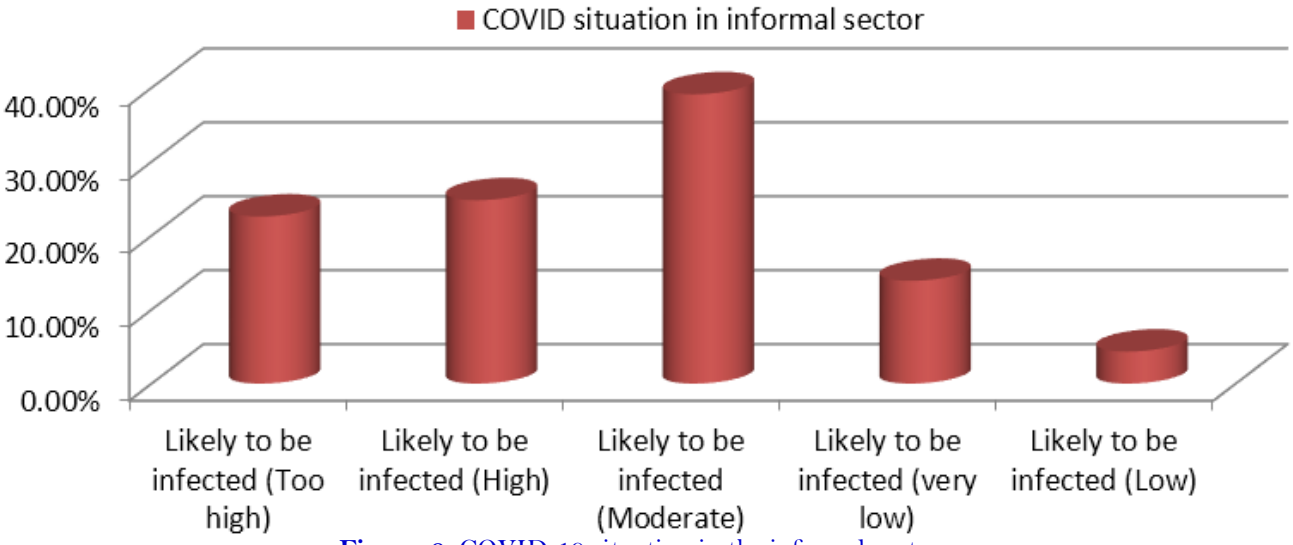

Figure-8. COVID-19 situation in the informal sector. 


\subsection{Availability of Medical Services}

This study reveals the experience of mass people about the availability of medical services after the outbreak of a pandemic. People have had the worst time getting health care in the 1st quartile of the pandemic. According to $95.48 \%$ of the people, the health service was completely disrupted at that time. Mathew, Deborah, Karonga, and Rumbidzai (2020) also found almost the same result in the case of another developing country Zambia, where 100\% of respondents mentioned poor access to reproductive health care due to lockdown and other restrictions. Although the situation improved a little bit later, about $85.56 \%$ and $90.52 \%$ of people said that the health care service was lower than normal in the 2 nd and 3 rd quartile of the pandemic respectively. The respondents who availed of health care service during the pandemic mostly emphasize three causes of decreasing health care service during the pandemic. Among them, 66.27\% of respondents claimed that the doctors did not see the patients for fear of Corona infection, especially in the 1st quartile of the pandemic. Another $45.34 \%$ of them claimed the doctors were busy with COVID-19 positive patients.

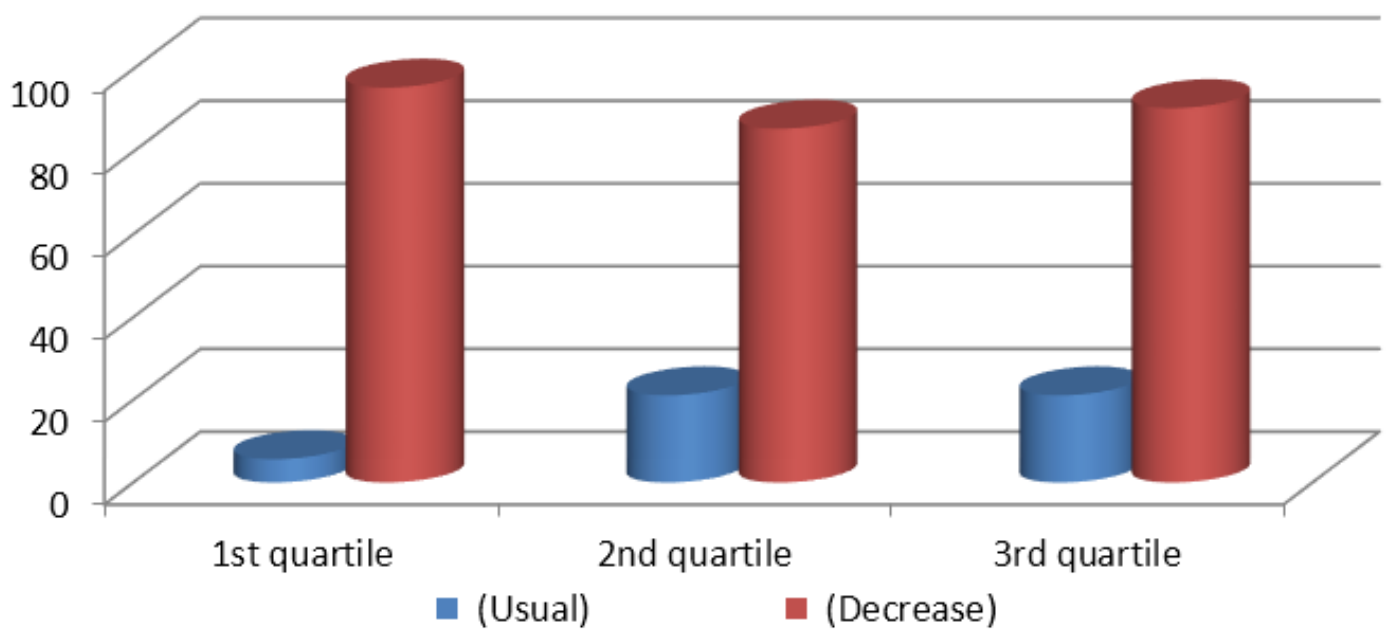

Figure-9. Medical services after the outbreak of COVID-19

Lastly, $16.27 \%$ of respondents claimed that health care services became scarcer due to the high fees of the doctors. During the 1st, 2nd, and 3rd quartile of the pandemic 5.64\%, $21.08 \%$, and $21.08 \%$ of respondents claimed the health service was as usual as before, which is shown in Figure 9. Their experience was different for various reasons like they were usually in touch with the quack doctors who were readily available during the pandemic. The study also found that about $30.64 \%$ of the total respondent did not need health care during the mentioned three quartiles of the pandemic.

\subsection{The Psychological Crisis}

The COVID-19 pandemic has caused the rhythm of normal family relationships to collapse. Financial pressure, loss of child care, distance with relatives and family members, anxiety, mental depression, and suicidal tendency has been exceedingly challenging for families. About $60 \%-69 \%$ of respondents said that the epidemic has deteriorated family relations Table 4 .

Table-4. The impact on the family relationship during the pandemic

\begin{tabular}{c|c|c|c|c|c}
\hline \multicolumn{2}{c|}{$\mathbf{1}^{\text {st }}$ quartile } & \multicolumn{2}{c|}{$\mathbf{2}^{\text {nd }}$ quartile } & \multicolumn{2}{c}{$3^{\text {rd }}$ quartile } \\
\hline Usual & Worsen & Usual & Worsen & Usual & Worsen \\
\hline $32.25 \%$ & $59.67 \%$ & $31.45 \%$ & $68.54 \%$ & $39.51 \%$ & $60.48 \%$ \\
\hline
\end{tabular}

Moreover, the study found that declining incomes and the resulting poverty were the main causes of family tension. Likewise, the pandemic has been stressful for most of the parents as a result; the children were beaten about 
$12 \%$ more than usual. One of the mentionable findings of the study is that there were no divorces among the respondent groups and $21 \%$ of the households did not have any negative changes in the family (Figure 10).
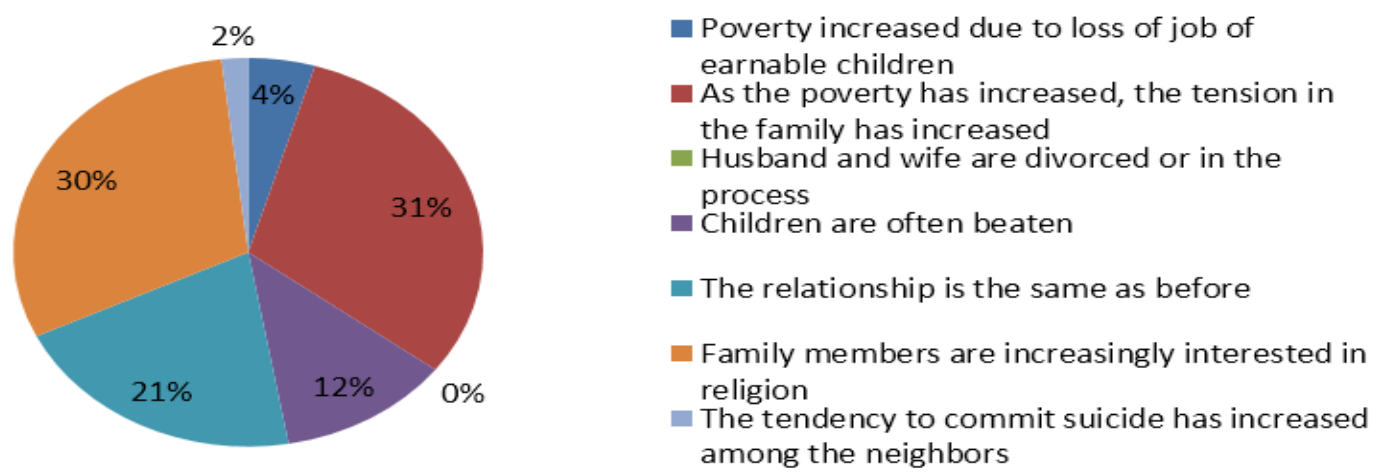

Figure-10. Nature of the family relationship during the pandemic.

\subsection{The impact on Pastime or Recreation}

After the outbreak of the COVID-19 pandemic, The Government of Bangladesh declared special "general leave" from 26 March in the name of "lockdown" and extended it up to 30 May 2020 in seven different time slots.

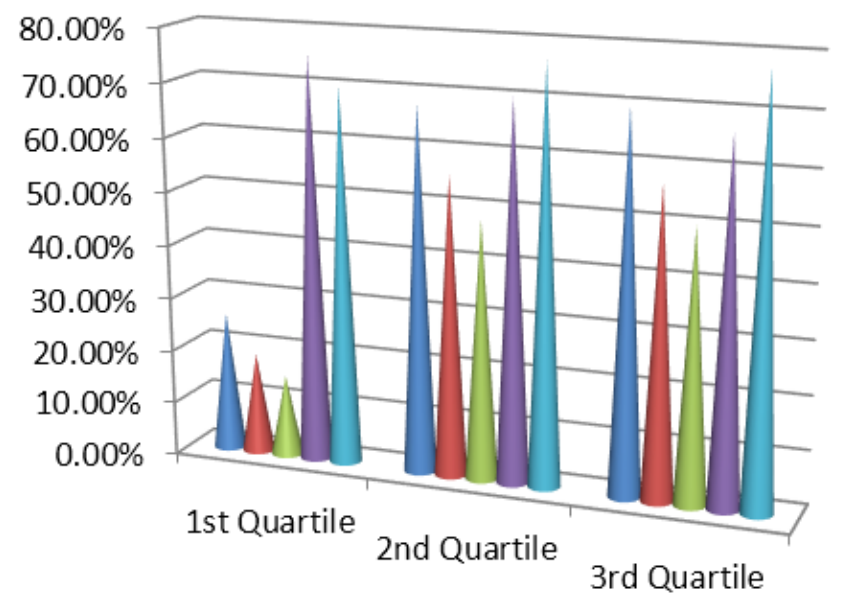

\section{Visiting native village for festivals}

Attending family programs

Hangout at weekend

\section{Watching TV}

Engaging social media

Figure-11. Nature of respondents' pastime during the pandemic

This study finds that in the 1st quartile of the ongoing pandemic (see Figure 11), due to restrictions on the movement of the long-distance transport services and poor income and savings of households only $25 \%$ of respondents were visited the native village for celebrating different festivals. Other means of recreation like attaining family programs, weekly hangouts were also almost off in the 1st quartile. Only $18.61 \%$ of respondents attended their family programs and $15.14 \%$ of respondents were visited different places for hangout purposes at weekends in the 1 st quartile. But in the 1 st quartile, we can see that more than $70 \%$ of respondents spent their time watching television or engaging social sides. In the 2 nd and 3rd quartile, people were used to new normal life that why all means of recreation were gradually increased. Almost $70 \%$ of respondents celebrated their festivals with their near ones together, $58 \%$ of respondents met their relatives at weekends in the 2 nd and 3rd quartile. This study also finds that watching television was as usual in both quartiles and $77 \%$ of respondents were engaged with social sides in the 2 nd quartile but a little bit falls in the $3 r d$ quartile.

\section{CONCLUSIONS}

The COVID - 19 pandemics disrupted workers' livelihood opportunities in Bangladesh's informal sector, including their socioeconomic, physiological, psychological, and cultural correlations. Lockdown and quarantine 
interventions abruptly altered their employment contracts, social security, and job requirements, rather than expanding their leisure horizons, such as visiting their hometown during religious festivals, participating in family programs, or hanging out weekly. Furthermore, employees in the informal sector became ill as a result of COVID19 and developed minor complications after recovery. Specifically, the analysis aims to identify the danger and fragility that arose from the emergence of COVID-19 via an exploratory study so that policymakers can enact protective measures for this vulnerable population, which makes up the majority of the country's labor force.

Our findings are based on a longitudinal study that included 372 valid respondents from Dhaka and Chattogram districts, which were classified into 13 different categories of employment status. The research looked at socioeconomic, physiological, psychological, health-care services, and recreational factors to see how COVID-19 affected them.

The situation of the informal workers' jobs before and after the pandemic is very different, as they have to change their profession and job institution many times. The study discovers a strong link between their happiness, jobs, and productivity, putting them at risk of falling into poverty. Since they are involved in the income-generating process and more than half of their children's respondents have no interest in education.

In comparison to the national scenario (the rate of positivity is 13.75 percent), this evidence indicates that health disasters are no longer feared (7.25 percent positivity rate of getting infected) among the staff in the informal sector of the top two infected districts, Dhaka and Chattogram. This research also shows how people feel about the possibility of contracting the virus. The health service was disrupted in the first quartile of the pandemic, out of the three quartiles listed. The lockout imposed by COVID-19 has disrupted the usual rhythm of family relationships by not ensuring that basic needs are met. Furthermore, the study shows that the majority of respondents in the first quartile of the current pandemic felt the epidemic and that it harmed leisure activities.

Based on the results of the study, several actionable guidelines for dealing with possible pandemics have been suggested. To begin, it was suggested that providing basic support to vulnerable people and good governance reduce the psychological and socioeconomic impact of the COVID-19 outbreak in Bangladesh. Second, establishing universal social security to aid the recovery of productive economic units, boost productivity, and ease the transition to the formal sector to expand formal employment opportunities. Finally, given the results of this report, the government must ensure that these informal workers' children have access to online educational resources.

Funding: This study received no specific financial support.

Competing Interests: The authors declare that they have no competing interests.

Acknowledgement: All authors contributed equally to the conception and design of the study.

\section{REFERENCES}

Akter, S. (2020). Covid-19 and Bangladesh: Threat of unemployment in the economy. Paper presented at the International EMI Entrepreneurship and Social Sciences Congress Proceedings E-Book.

Aneja, R., \& Ahuja, V. (2021). An assessment of socioeconomic impact of COVID-19 pandemic in India. Journal of Public Affairs, 21(2), e2266. Available at: https://doi.org/10.1002/pa.2266.

Bangladesh Bank. (2020). Monthly economic trendds October 2020. Dhaka, Bangladesh: Statistics Department, Bangladesh Bank.

Bodrud-Doza, M., Shammi, M., Bahlman, L., Islam, A. R. M., \& Rahman, M. (2020). Psychosocial and socio-economic crisis in Bangladesh due to COVID-19 pandemic: A perception-based assessment. Frontiers in Public Health, 8, 341. Available at: https://doi.org/10.3389/fpubh.2020.00341.

Buheji, M., da Costa Cunha, K., Beka, G., Mavric, B., De Souza, Y., da Costa Silva, S. S., \& Yein, T. C. (2020). The extent of covid-19 pandemic socio-economic impact on global poverty. A global integrative multidisciplinary review. American Journal of Economics, 1O(4), 213-224. Available at: https://doi.org/10.5923/j.economics.20201004.02.

Daly, M., Sutin, A. R., \& Robinson, E. (2020). Longitudinal changes in mental health and the COVID-19 pandemic: Evidence from the UK Household longitudinal study. Psychological Medicine, 13, 1-10. Available at: https://doi.org/10.1017/s0033291720004432.

Dubey, M. J., Ghosh, R., Chatterjee, S., Biswas, P., Chatterjee, S., \& Dubey, S. (2020). COVID-19 and addiction. Diabetes £ீ Metabolic Syndrome: Clinical Research Ë Reviews, 14(5), 817-823.

FAO. (2020). Impact of COVID-19 on informal workers. Rome, Italy: FAO. 
Ferreira dos Santos, G., de Santana Ribeiro, L. C., \& Barbosa de Cerqueira, R. (2020). The informal sector and Covid-19 economic impacts: The case of Bahia, Brazil. Regional Science Policy E Practice, 12(6), 1273-1285. Available at: https://doi.org/10.1111/rsp3.12366.

Hasan, M., Rabbani, M., \& Abdulla, A. (2021). Socioeconomic impact of COVID-19 in MENA region and the role of islamic finance. International Journal of Islamic Economics and Finance, 4(1), 51-78. Available at: https://doi.org/10.18196/ijief.v4i1.10466.

Islam, S., Islam, R., Mannan, F., Rahman, S., \& Islam, T. (2020). COVID-19 pandemic: An analysis of the healthcare, social and economic challenges in Bangladesh. Progress in Disaster Science, 8, 100135. Available at: https://doi.org/10.1016/j.pdisas.2020.100135.

Jena, P. K. (2020). Impact of pandemic COVID-19 on education in India. International Journal of Current Research, 12(7), 1258212586.

Joko, P. A., Bagas, A., \& Ikhwan, A. (2020). The impacts of COVID-19 pandemic to informal economic sector in Indonesia: Theoretical and empirical comparison. Paper presented at the International Conference on Science and Technology, (October), 0-8.

Kartseva, M. A., \& Kuznetsova, P. O. (2020). The economic consequences of the coronavirus pandemic: Which groups will suffer more in terms of loss of employment and income? Population and Economics, 4(2), 26-33. Available at: https://doi.org/10.3897/popecon.4.e53194.

Komin, W., Thepparp, R., Subsing, B., \& Engstrom, D. (2021). Covid-19 and its impact on informal sector workers: A case study of Thailand. Asia Pacific Journal of Social Work and Development, 31(1-2), 80-88. Available at: https://doi.org/10.1080/02 185385.2020.1832564.

Mathew, N., Deborah, I., Karonga, T., \& Rumbidzai, C. (2020). The impact of COVID-19 lockdown in a developing country: Narratives of self-employed women in Ndola, Zambia. Health Care for Women International, 41(11-12), 1370-1383. Available at: https://doi.org/10.1080/07399332.2020.1823983.

Ozili, P. (2020). COVID-19 in Africa: Socio-economic impact, policy response and opportunities. International Journal of Sociology and Social Policy, Ahead-of-print. Available at: https://doi.org/10.1 108/IJSSP-05-2020-0171.

Pancani, L., Marinucci, M., Aureli, N., \& Riva, P. (2021). Forced social isolation and mental health: A study on 1,006 Italians under COVID-19 lockdown. Frontiers in Psychology, 12, 1540. Available at: https://doi.org/10.3389/fpsyg.202 1.663799.

Porsse, A. A., de Souza, K. B., Carvalho, T. S., \& Vale, V. A. (2020). The economic impacts of COVID-19 in Brazil based on an interregional CGE approach. Regional Science Policy \& Practice, 12(6), 1105-1121. Available at: https://doi.org/10.1111/rsp3.12354.

Russo, D., Hanel, P. H., Altnickel, S., \& van Berkel, N. (2021). Predictors of well-being and productivity among software professionals during the COVID-19 pandemic-a longitudinal study. Empirical Software Engineering, 26(4), 1-63. Available at: https://doi.org/10.1007/s10664-02 1-09945-9.

Sen, M., Honavar, S. G., Sharma, N., \& Sachdev, M. S. (2021). COVID-19 and eye: A review of ophthalmic manifestations of COVID-19. Indian Journal of Ophthalmology, 69(3), 488-509. Available at: https://doi.org/10.4103/ijo.ijo_297_21.

Sumalatha, B., Bhat, L. D., \& Chitra, K. (2021). Impact of covid-19 on informal sector: A study of women domestic workers in India. The Indian Economic Journal, 69(3), 441-461. Available at: https://doi.org/10.1177/00194662211023845.

Zhang, S. X., Wang, Y., Rauch, A., \& Wei, F. (2020). Unprecedented disruption of lives and work: Health, distress and life satisfaction of working adults in China one month into the COVID-19 outbreak. Psychiatry Research, 288, 112958. Available at: https://doi.org/10.1016/j.psychres.2020.112958. 